\title{
Formation of Porous Carbon Materials with in Situ Generated NaF Nanotemplate
}

\author{
Chih-Hao Huang, ${ }^{\dagger}$ Yu-Hsu Chang, ${ }^{\dagger}$ Hsiao-Wan Wang,,${ }^{\ddagger}$ Soofin Cheng, ${ }^{\ddagger}$ Chi-Young Lee, ${ }^{\S}$ and \\ Hsin-Tien Chiu*, $\dagger$ \\ Department of Applied Chemistry, National Chiao Tung University, \\ Hsinchu, Taiwan, 30050, Republic of China, Department of Chemistry, National Taiwan University, \\ Taipei, Taiwan, 10673, Republic of China, and Materials Science Center, National Tsing Hua University, \\ Hsinchu, Taiwan, 30043, Republic of China
}

Received: March 27, 2006; In Final Form: April 27, 2006

\begin{abstract}
Porous carbon materials with pore sizes from 3 to $200 \mathrm{~nm}$ were synthesized by reacting hexafluorobenzene with $\mathrm{Na}$ liquid at $623 \mathrm{~K}$. NaF crystals, a byproduct formed in the reaction, acted as nanotemplate to assist the pore formation. By employing hexafluorobenzene to react with $\mathrm{Na}$ incorporated within the channels (diameter $200 \mathrm{~nm}$ ) of anodized aluminum oxide (AAO) membranes at 323-623 K, the carbon material can be fabricated into aligned porous nanotube arrays (ca. $250 \mathrm{~nm}$ in diameter, ca. $20 \mathrm{~nm}$ in wall thickness, ca. $0.06 \mathrm{~mm}$ in length, and ca. 3-90 nm in pore diameter). These materials were characterized by X-ray diffraction, scanning and transmission electron microscopy, X-ray energy dispersive spectroscopy, electron diffraction, thermal gravimetric analysis, and nitrogen physical adsorption experiments.
\end{abstract}

\section{Introduction}

Porous materials provide excellent opportunities in numerous technological applications. ${ }^{1,2}$ Among different types of porous materials, porous carbon ( $\mathrm{p}-\mathrm{C})$ has high potential as the component in catalysis, adsorption, sensing, and fuel-cell systems. ${ }^{3-6}$ Many types of carbon materials with different pore sizes have been fabricated through replica approaches employing various zeolites or silica as the templates and casts. ${ }^{7-12}$ Another frequently used method employs defluorination of PTFE, poly(tetrafluoroethylene), by alkali metals. ${ }^{13-15}$ In the present work, we wish to report an efficient new synthesis of $\mathrm{p}-\mathrm{C}$ by reacting the vapor of $\mathrm{C}_{6} \mathrm{~F}_{6}$ with $\mathrm{Na}$ metal. The growth is an interesting example of a phase separation assisted self-templating process. Moreover, template-assisted growth of carbon nanotubes (CNT) has been demonstrated to be an efficient method to produce aligned arrays of CNT. ${ }^{16-23}$ By coupling the reaction between $\mathrm{C}_{6} \mathrm{~F}_{6}$ and $\mathrm{Na}$ with a reactive-template strategy reported before, ${ }^{24}$ which employs anodic aluminum oxide (AAO) membrane filled with $\mathrm{Na}$ metal as an active cast, arrays of porous CNT (p-CNT) can be fabricated.

\section{Experimental Section}

Synthesis of p-C. Na metal was prepared by pyrolyzing $\mathrm{NaH}$ ( $0.15 \mathrm{~g}, 6.3 \mathrm{mmol}$, Aldrich) under Ar atmosphere on a silica boat inside a tube furnace at $623 \mathrm{~K}$ for $1 \mathrm{~h}$. To the as-formed $\mathrm{Na}$ metal at $623 \mathrm{~K}, \mathrm{C}_{6} \mathrm{~F}_{6}(99 \%$, Aldrich) vaporized at $298 \mathrm{~K}$ was introduced by bubbling under a constant flow of $\mathrm{Ar}(5 \mathrm{sccm})$ for $4 \mathrm{~h}$. The as-prepared black product was further washed in refluxing distilled water $(300 \mathrm{~mL})$ overnight. The solid product was collected, rinsed with distilled water, and dried at $373 \mathrm{~K}$ in air.

Synthesis of p-CNT. Na@AAO was prepared by pyrolyzing $\mathrm{NaH}$ (0.15 g, $6.3 \mathrm{mmol}$, Aldrich) on AAO (Whatman Anodisc 13 , pore diameter of $200 \mathrm{~nm}$, thickness of $60 \mu \mathrm{m}$ ) at $623 \mathrm{~K}$ for $1 \mathrm{~h}$ under an Ar atmosphere. ${ }^{24}$ The as-prepared Na@AAO was reacted with $\mathrm{C}_{6} \mathrm{~F}_{6}(99 \%$, Aldrich), maintained at $298 \mathrm{~K}$, and

\footnotetext{
* Address correspondence to this author. E-mail: htchiu@cc.nctu.edu.tw

National Chiao Tung University.

$\doteqdot$ National Taiwan University.

$\S$ National Tsing Hua University.
}

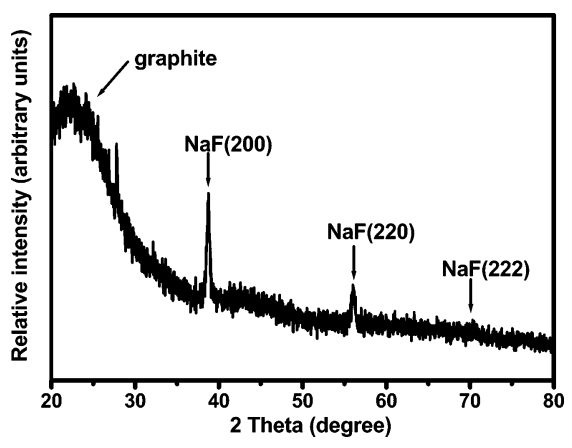

Figure 1. XRD of an as-formed raw product prepared at $623 \mathrm{~K}$.

bubbled with the assistance of a constant flow of $\mathrm{Ar}(5 \mathrm{sccm})$ at 323 and $623 \mathrm{~K}$ for $4 \mathrm{~h}$ to generate black products. The as-prepared products were further washed in refluxing distilled water (300 mL) overnight. Then, the AAO was removed by immersion in $48 \% \mathrm{HF}$ at room temperature for $9 \mathrm{~h}$. Finally, the products were filtered, rinsed with distilled water, and dried at $373 \mathrm{~K}$ in air.

Characterization of $\mathbf{p}-\mathbf{C}$ Materials. A scanning electron microscope (JEOL JSM-6330F at $15 \mathrm{kV}$ and HITACHI S-4000 at $25 \mathrm{kV}$ ) and a high-resolution transmission electron microscope (JEOL JEM-4000 at $400 \mathrm{kV}$ ) were used to observe the sample morphology. X-ray energy dispersive spectroscopy was used to confirm the element composition of the samples. Crystallinity of the samples was investigated by an X-ray diffractometer (BRUKER AXS D8 ADVANCE, $\mathrm{Cu} \mathrm{K} \alpha$ radiation, $40 \mathrm{kV}$ and $40 \mathrm{~mA}$ ). A physical adsorption instrument (Micromeritics ASAP 2010 , at $77 \mathrm{~K}$ with $\mathrm{N}_{2}$ gas) was used to investigate surface area and pore size distribution of the samples. Thermal gravimetric analysis (TGA) was carried out on a Pyris Diamond TG/DTA instrument (heating rate of $5 \mathrm{deg} / \mathrm{min}$ from room temperature to $900{ }^{\circ} \mathrm{C}$, air flow rate at $100 \mathrm{~mL} / \mathrm{min}$ ).

\section{Results}

Preparation and Characterization of p-C. In general, via a Wurtz-type coupling reaction, ${ }^{25}$ the vapor of $\mathrm{C}_{6} \mathrm{~F}_{6}$ was reacted with $\mathrm{Na}$ metal, prepared by pyrolyzing $\mathrm{NaH}$ under Ar, at 623 


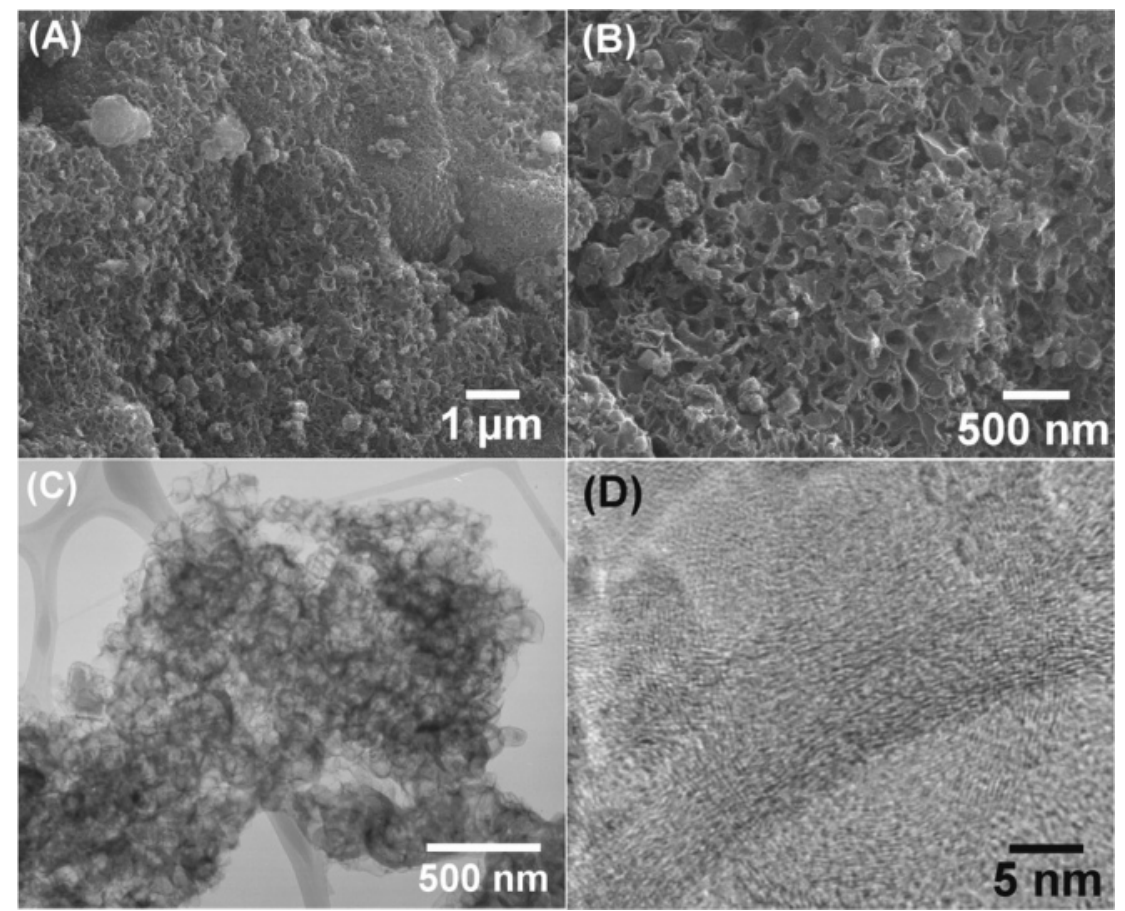

Figure 2. Images of p-C prepared at $623 \mathrm{~K}$.: (A) low and (B) high magnification SEM and (C) low- magnification and (D) high-resolution TEM.

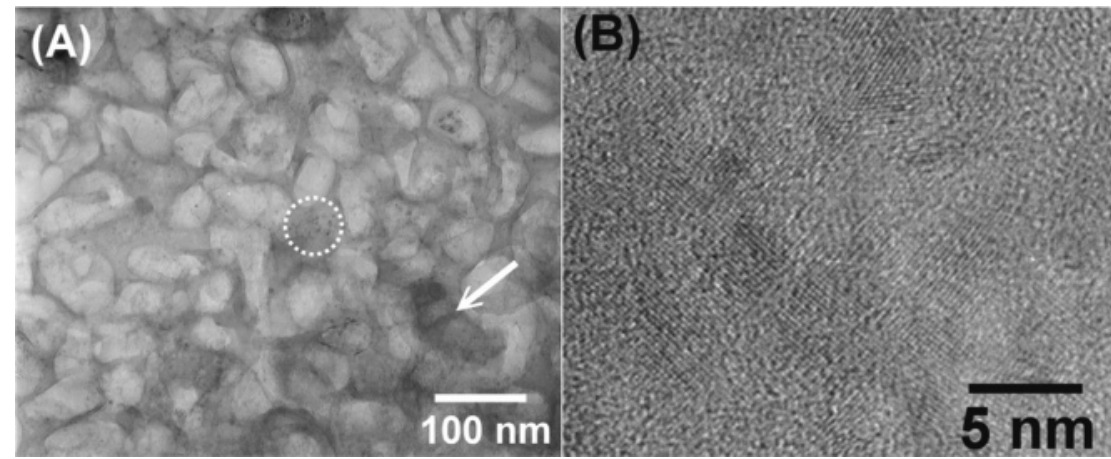

Figure 3. TEM images of phase separated $\mathrm{p}-\mathrm{C}$ and $\mathrm{NaF}$ : (A) low magnification image showing NaF crystals pointed out by the arrow and (B) high-resolution image of $\mathrm{NaF}$ nanocrystals selected from the circled area in part $\mathrm{A}$.

$\mathrm{K}$ for $1 \mathrm{~h}$ to offer a dark solid product. As described in the next section, the reaction can be performed at a temperature as low as $323 \mathrm{~K}$. As shown in Figure 1, X-ray diffraction (XRD) of the solid produced at $623 \mathrm{~K}$ displays a diffraction pattern that is composed of a broad (002) reflection from graphite (JCPDS 23-0064) and (200), (220), and (222) reflections from $\mathrm{NaF}$ (JCPDS 36-1455). No other significant structural information was observed. After the sample was washed with distilled water, the salt was removed and the black solid product was collected. Figure $2 \mathrm{~A}$ is a typical scanning electron microscopic (SEM) image of the isolated material. In the enlarged image, Figure $2 \mathrm{~B}$, morphology of the material is shown to have innumerable pores with diameters less than $200 \mathrm{~nm}$. X-ray energy dispersive spectroscopy (EDX) confirms that the solid is composed of carbon while the concentrations of sodium and fluorine are below the detection limits. A low-magnification transmission electron microscopic (TEM) image in Figure 2C also shows the porous nature of the solid product, with pore diameters less than $200 \mathrm{~nm}$. In a high-resolution transmission electron microscopic (HRTEM) image (Figure 2D) of the sample, the presence of fringes spaced ca. $0.35 \mathrm{~nm}$ apart is observed. Since the fringes are not well ordered, we suggest that the edges of the $\mathrm{p}-\mathrm{C}$ have a short-range ordering of graphite texture. The thickness of the $\mathrm{p}-\mathrm{C}$ wall, deduced from the image, is $3-15 \mathrm{~nm}$. Occasionally,
$\mathrm{NaF}$ nanoparticles can be observed inside $\mathrm{p}-\mathrm{C}$ by TEM. For example, at point indicated by the arrow in Figure $3 \mathrm{~A}$, the presence of a $\mathrm{NaF}$ crystal ca. $80 \mathrm{~nm}$ in size is identified by EDX. In addition, from the circled area in Figure 3A, several minute nanocrystals with sizes of $2-4 \mathrm{~nm}$ are observed by HRTEM, as shown in Figure 3B. The lattice fringes are spaced $0.23 \mathrm{~nm}$ apart, which coincides well with the $\{200\}$ interplanar distance of NaF (JCPDS 36-1455). This confirms that the nanosized $\mathrm{NaF}$ crystals acted as the templates for the formation of the porous structure.

Preparation and Characterization of p-CNT. Previously, we demonstrated that by pyrolyzing $\mathrm{NaH}$ on top of AAO membranes, the as-formed Na flowed into the channels of AAO and produced reactive templates $\mathrm{Na} @ \mathrm{AAO} .^{24} \mathrm{By}$ reacting $\mathrm{Na} @ \mathrm{AAO}$ with $\mathrm{C}_{6} \mathrm{Cl}_{6}$, amorphous carbon nanotubes were fabricated inside the AAO cast. On the basis of the product morphology, we concluded that metallic $\mathrm{Na}$ existed as nanotubes inside the AAO channels of $\mathrm{Na} @ \mathrm{AAO}$. We extend the strategy in this study. By employing $\mathrm{C}_{6} \mathrm{~F}_{6}$ to react with $\mathrm{Na} @ \mathrm{AAO}$ at 323 and $623 \mathrm{~K}$, black products were insolated. After the AAO template and the salt were removed, the products were investigated by electron microscopy. A low-magnification SEM image of the product prepared at $323 \mathrm{~K}$ after the AAO cast was removed is shown in Figure 4A. It displays that the sample 

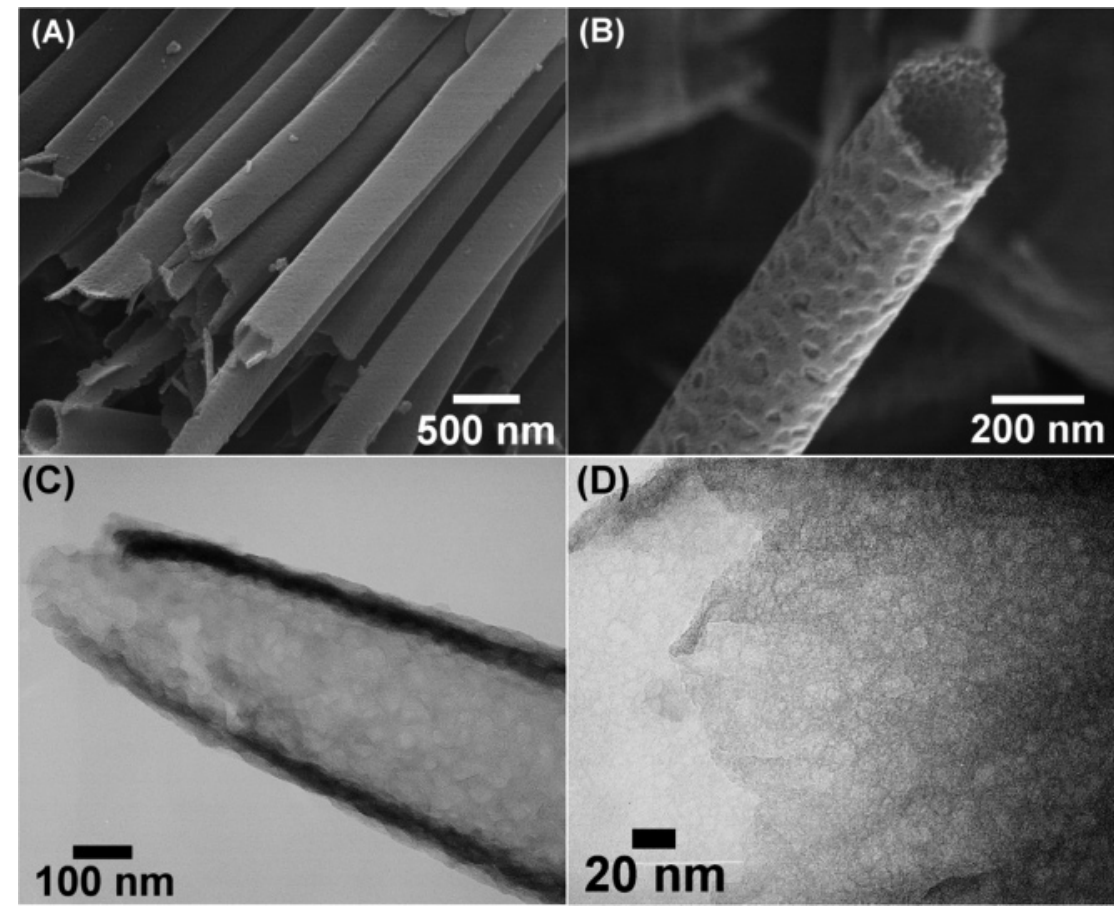

Figure 4. Images of p-CNT prepared at $323 \mathrm{~K}$ : (A) low and (B) high magnification SEM and (C) low- and (D) high-magnification TEM.

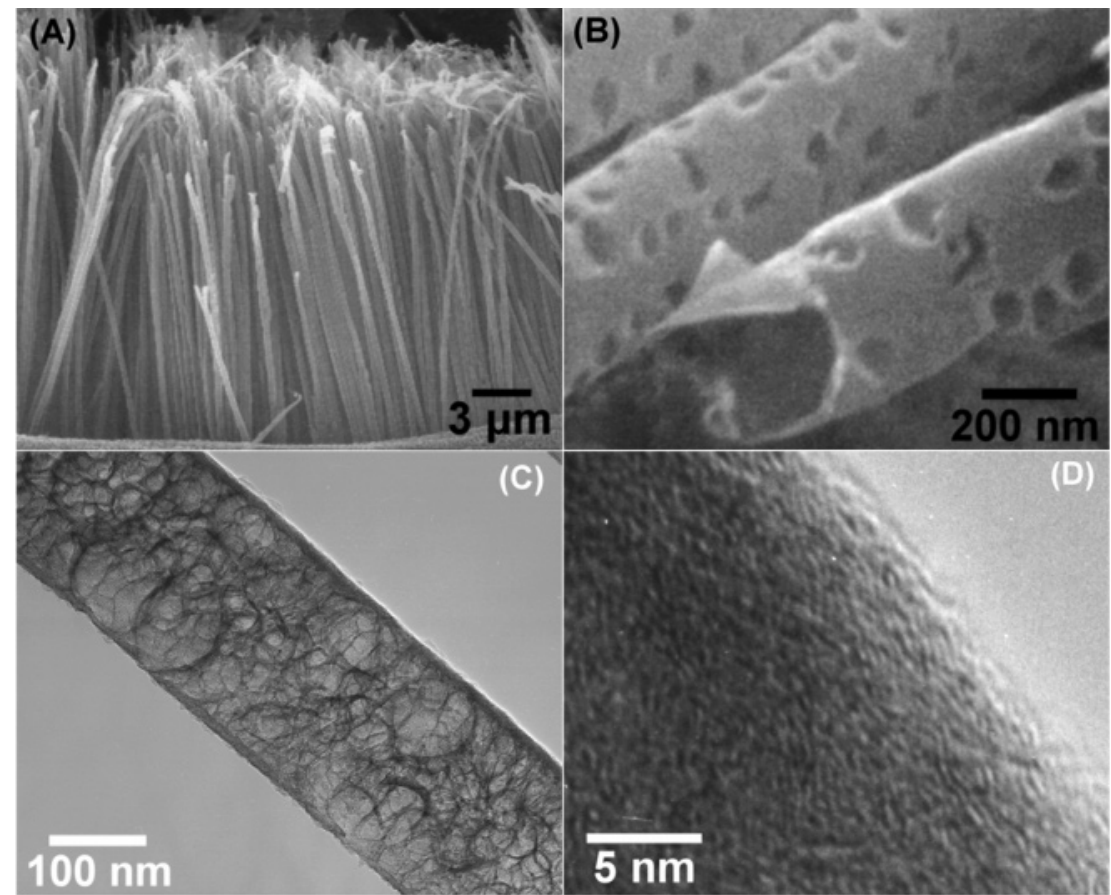

Figure 5. Images of p-CNT prepared at $623 \mathrm{~K}$ : (A) low and (B) high magnification SEM and (C) low- and (D) high-resolution TEM.

is an aligned array of nanotubes with diameters of 200-250 $\mathrm{nm}$. This is close to the channel diameter of the AAO template. An EDS study confirms that the material is composed of carbon. From other SEM images, the length of the nanotubes is estimated to be $60 \mu \mathrm{m}$, which is close to the thickness of the AAO membrane. Figure 4B shows an enlarged SEM image of a p-CNT with undulate inner and outer surfaces. On the basis of the results discussed in the previous section, the unevenness of the surfaces is attributed to the presence of pores generated by the byproduct NaF. A TEM image (Figure 4C) of a tube also shows an average diameter of $220 \mathrm{~nm}$, which is comparable to the SEM observation. In Figure 4D, an HRTEM image shows the detailed microstructure of a p-CNT. It reveals a wall thickness of ca. 15-20 nm and numerous pores of several nanometers inside the wall. Thus, we successfully fabricated, via a simple process, a new type of $\mathrm{p}$-CNT from this unique self-templating and casting approach.

From SEM images and EDX studies, the sample prepared at $623 \mathrm{~K}$ is also identified to be an aligned array of p-CNT (lengths of ca. $60 \mu \mathrm{m}$, diameters of ca. $200-300 \mathrm{~nm}$, and pore sizes of ca. 20-100 nm). Examples of low- and high-magnification images are shown in Figure 5, panels A and B, respectively. In Figure 5C, a TEM image of an individual p-CNT shows the presence of innumerable pores of $15-90 \mathrm{~nm}$ in the wall, which correlates well with the SEM observation. An HRTEM image (Figure 5D), selected from the edge of the p-CNT shown in Figure 5C, displays textured graphene layers. The overall pore structure in $\mathrm{p}-\mathrm{CNT}$ is nearly identical with that of $\mathrm{p}-\mathrm{C}$ discussed 

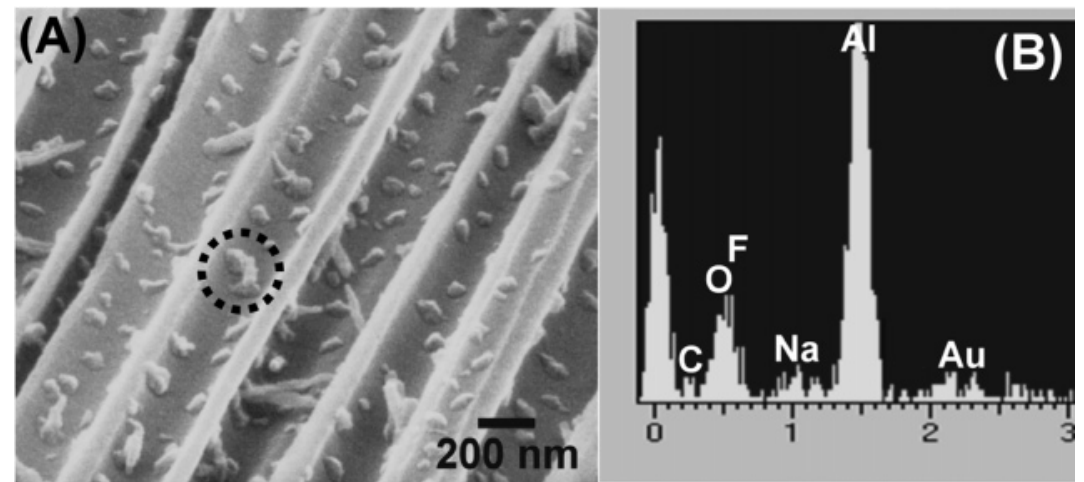

Figure 6. (A) Cross sectional SEM image of AAO after removal of p-CNT prepared at $623 \mathrm{~K}$ showing crystals in the channels and (B) EDS from the circled area in part A.

above. A TGA result showed that a p-CNT sample, annealed at $1173 \mathrm{~K}$ under vacuum followed by removing the AAO template, was oxidized in air at $710 \mathrm{~K}$. The sharp weight loss suggests that the sample contained less ordered carbon structure. ${ }^{26}$ The process removed ca. $63 \%$ weight of the material in the sample. The residue, which was stable up to $1173 \mathrm{~K}$, is assigned to unremoved $\mathrm{NaF}$ byproduct.

The following observations further support the role of the $\mathrm{NaF}$ byproduct as an in situ generated nanotemplate for pore formation. Figure 6A shows an enlarged cross-sectional SEM view of an AAO membrane after p-CNT formed at $623 \mathrm{~K}$ was removed from the cast. On the exposed channel surface, solid islands with sizes of several tens of nanometers are observed. An EDX study (Figure 6B) of an island, selected from the circled area in Figure 6A, reveals the presence of $\mathrm{Na}$ and $\mathrm{F}$. Consequently, the islands are identified to be $\mathrm{NaF}$ crystals. The crystal size and shape are in good agreement with the pore structures observed in Figure 5B,C. Thus, we conclude that the $\mathrm{NaF}$ nanocrystals and the AAO membrane acted as the cast to influence the p-CNT structure cooperatively. The NaF worked as the in situ generated nanotemplate, which assisted the pore formation, while the AAO membrane performed the role of the cast, which aided the tubular shape development.

BET Analysis of p-C Materials Prepared at $623 \mathrm{~K}$. From the SEM and TEM studies discussed above, the carbon materials possessed pores with sizes ranging from several to several tens of nanometers. Typical nitrogen adsorption-desorption isotherms of $\mathrm{p}-\mathrm{C}$ and $\mathrm{p}-\mathrm{CNT}$ prepared at $623 \mathrm{~K}$ are shown in Figure 7 , panels $\mathrm{A}$ and $\mathrm{B}$, respectively. In the region of middle and high $P / P_{0}$, the amount of $\mathrm{N}_{2}$ adsorption increases sharply. The phenomenon, a steep increase in the isotherm at high pressures $\left(P / P_{0} \rightarrow 1\right)$, confirms that large macropores are present in the materials. In addition, large hystereses are observed in Figure 7. This is evidence for a network pore system with distinct polydispersity in size..$^{27,28}$ The observation is in good agreement with the TEM images in Figures 2C and 5C. Estimated from Figure 7A, the Brunauer-Emmett-Teller (BET) surface area is $161 \mathrm{~m}^{2} \mathrm{~g}^{-1}$. By using Barret-Joyner-Halenda (BJH) method, the smallest pore size in $\mathrm{p}-\mathrm{C}$ can be calculated from the desorption branch of the nitrogen isotherm. The reason the desorption branches, instead of the adsorption ones, were used is explained below. According to the Kelvin equation, ${ }^{27}$ the desorption branch of the isotherms is usually more reasonable to derive the diameters of cylindrical pores when the contact angle between the adsorbate, which was nitrogen in this study, and the pore wall is assumed to be zero. Nevertheless, the huge hysteresis loops of the isotherms of $\mathrm{p}-\mathrm{C}$ and $\mathrm{p}-\mathrm{CNT}$ materials indicate the pores could probably be described by an ink-bottle model. ${ }^{27}$ The rapid increase in adsorption volume in the
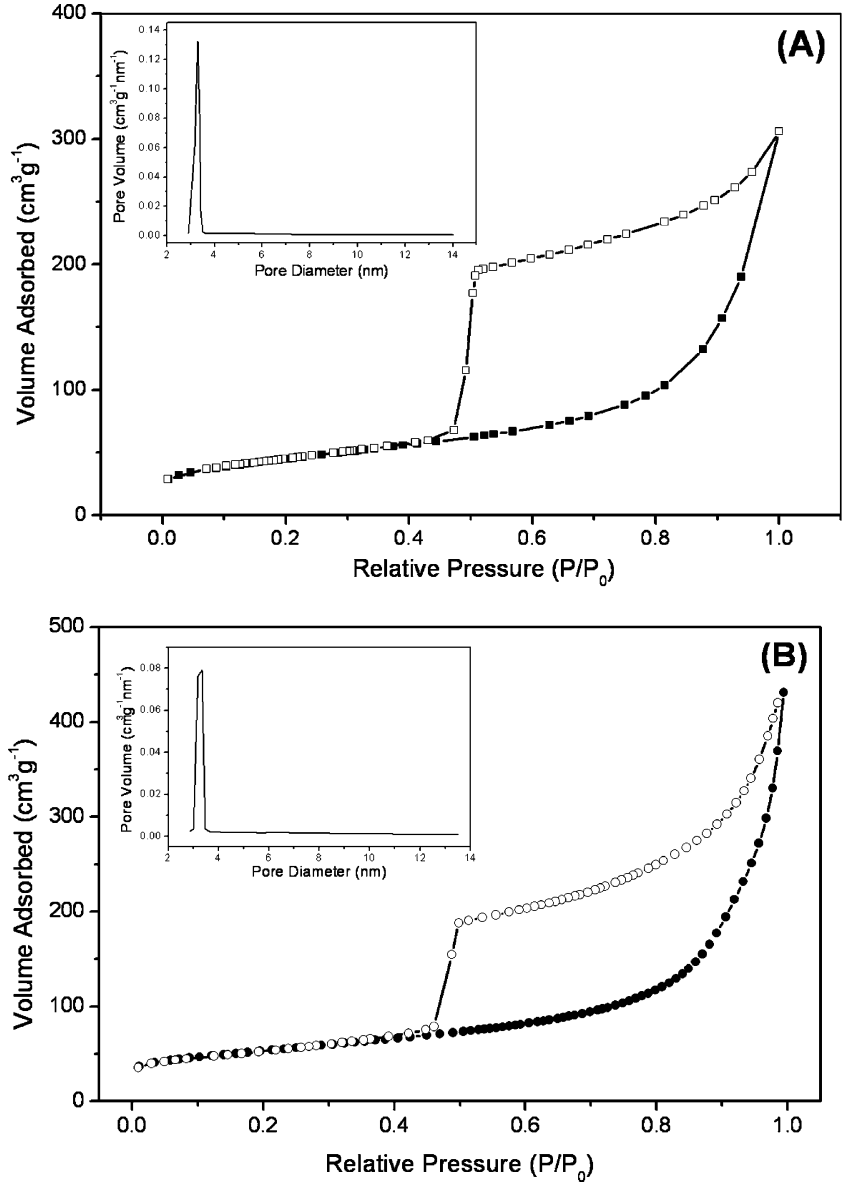

Figure 7. Nitrogen adsorption-desorption isotherms and $\mathrm{BJH}$ pore size distribution from the desorption branches (insets): (A) p-C ( $\mathbf{\square}$ : adsorption branch; $\square$ : desorption branch) and (B) p-CNT (-: adsorption branch; $\bigcirc$ : desorption branch).

adsorption branches at higher $P / P_{0}$ was related to the large diameter of the bottle shaped pores, while that in the desorption branches at lower $P / P_{0}$ was correlated to the smaller diameter of the neck. Thus, the pores of this region are estimated to be as small as $3-3.5 \mathrm{~nm}$. This agrees with the mesopores (sizes 2-4 nm) observed in Figure 3B, which formed after the $\mathrm{NaF}$ nanocrystals in the carbon matrix were removed. This is comparable to a previous study in which removal of fluorides from a carbon matrix by acid treatment was found to leave empty sites as pores. ${ }^{29}$ The BET surface area estimated from Figure $7 \mathrm{~B}$ is $183 \mathrm{~m}^{2} \mathrm{~g}^{-1}$. The calculated pore size distribution from the desorption branch, using the $\mathrm{BJH}$ method, also displays that the pores exhibit a size limit at 3-3.5 $\mathrm{nm}$. These 
SCHEME 1: Preparations of p-C and p-CNT

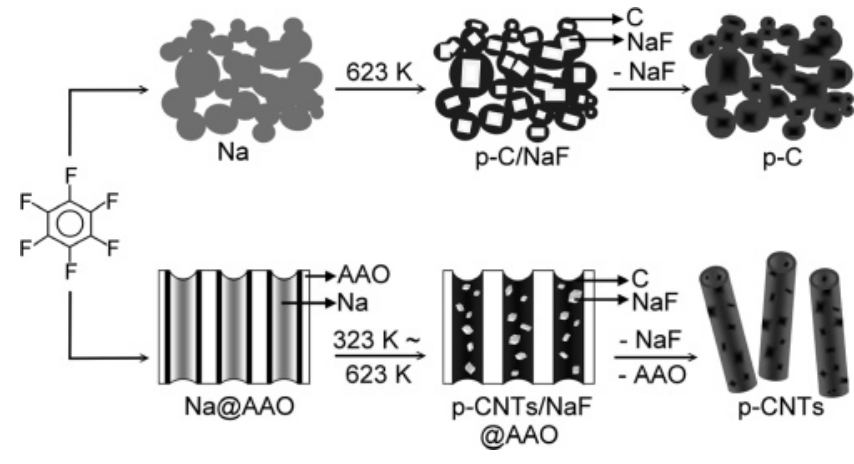

experimental data are comparable to the values reported recently in another study. ${ }^{11}$

\section{Discussion}

For summary, a scheme for the formation of $\mathrm{p}-\mathrm{C}$ materials by reacting $\mathrm{C}_{6} \mathrm{~F}_{6}$ with $\mathrm{Na}$ and $\mathrm{Na} @ \mathrm{AAO}$ is shown in Scheme 1. The process utilized the strong reducing capability of metallic $\mathrm{Na}$ to remove $\mathrm{F}$ atoms from $\mathrm{C}_{6} \mathrm{~F}_{6}$ and facilitated the solid carbon formation via a Wurtz-type coupling reaction. As shown in the TEM images in Figure 3, due to phase separation, the $\mathrm{NaF}$ byproducts of various sizes are incorporated within the carbon solid. This assists the formation of the macro- and mesoporous structures. Another possible origin of the mesopores, as suggested in the literature, is from the disordered stacking of graphene sheets shown in Figures $2 \mathrm{D}$ and $5 \mathrm{D} .{ }^{30}$ The p-CNT prepared from $\mathrm{C}_{6} \mathrm{~F}_{6}$ in this study shows significant structural difference from the $\mathrm{CNT}$, which had smooth nonporous walls, synthesized from $\mathrm{C}_{6} \mathrm{Cl}_{6}$ previously. ${ }^{24}$ The origin of this is proposed to be the difference in physical properties of the byproduct salts $\mathrm{NaF}$ and $\mathrm{NaCl}$. This includes the melting point and the energy of formation, which would affect the crystal sizes and their affinity to surroundings. In this study, as shown in Figures 3 and 6, we find that $\mathrm{NaF}$ adhere better to the AAO template and the as-formed carbon solid. ${ }^{31}$ This was not observed in the previous investigation employing $\mathrm{C}_{6} \mathrm{Cl}_{6}$ as the source of carbon. ${ }^{24}$

It is striking to discover that p-CNT can be formed at a temperature as low as $323 \mathrm{~K}$. This observation may be attributed to the high energy of formation of $\mathrm{NaF}$ and the highly exothermic reaction. ${ }^{31}$ The reaction rate probably is accelerated significantly within nanoscopic zones where the reaction between gaseous $\mathrm{C}_{6} \mathrm{~F}_{6}$ molecules and $\mathrm{Na}$ releases enough energy to overcome the overall reaction barrier.

\section{Conclusions}

By employing $\mathrm{C}_{6} \mathrm{~F}_{6}$ to react with $\mathrm{Na}$, a unique type of $\mathrm{p}-\mathrm{C}$ material was formed. The self-generated $\mathrm{NaF}$ acted as the nanotemplate to shape the carbon material into the observed porous structure. By using the reactive template $\mathrm{Na} @ \mathrm{AAO}$, the $\mathrm{p}-\mathrm{C}$ can be fabricated further into nanotubes with a structure significantly different from the Iijima type CNT. ${ }^{32,33}$ The process reported here is relatively low temperature and does not require plasma, autoclave, and catalyst assistance. We anticipate these new materials to be useful in many applications. For example, a preliminary investigation showed that $\mathrm{p}-\mathrm{CNT}$ retained essential nanostructural features after being graphitized at $3073 \mathrm{~K}$. We expect polymer chains could entangle this unique carbon material effectively by passing through the porous structure. ${ }^{34,35}$ This may offer a new type of low-density and high-strength composite material. Investigation is in progress.

Acknowledgment. This work was supported by the National Science Council of Taiwan, Republic of China.

Supporting Information Available: XRD pattern of asformed $\mathrm{p}-\mathrm{C}$ raw product and TGA of $\mathrm{p}-\mathrm{CNT}$. This material is available free of charge via the Internet at http://pubs.acs.org.

\section{References and Notes}

(1) Ying, J. Y.; Mehnert, C. P.; Wong, M. S. Angew. Chem., Int. Ed. Engl. 1999, 38, 56.

(2) Schüth, F. Angew. Chem., Int. Ed. 2003, 42, 3604.

(3) Che, G.; Lakshmi, B. B.; Fisher, E. R.; Martin, C. R. Nature 1998, $393,346$.

(4) Joo, S. H.; Choi, S. J.; Oh, I.; Kwak, J.; Liu, Z.; Terasaki, O.; Ryoo, R. Nature 2001, 412, 169.

(5) Dalton, A. B.; Collins, S.; Munoz, E.; Razal, J. M.; Ebron, V. H. Ferratis, J. P.; Coleman, J. N.; Kim, B. G.; Baughman, R. H. Nature 2003, $423,703$.

(6) Sakintuna, B.; Yurum, Y. Ind. Eng. Chem. Res. 2005, 44, 2893. 9,609 .

(7) Kyotani, T.; Nagai, T.; Inoue, S.; Tomita, A. Chem. Mater. 1997,

(8) Johnson, S. A.; Brigham, E. S.; Ollivier, P. J.; Mallouk, T. E. Chem. Mater. 1997, 9, 2448.

(9) Lee, J.; Yoon, S.; Hyeon, T.; Oh, S. M.; Kim, K. B. Chem. Commun. 1999, 2177.

(10) Ryoo, R.; Joo, S. H.; Kruk, M.; Jaroniec, M. Adv. Mater. 2001 13,677 .

(11) Kim, M.; Sohn, K.; Kim, J.; Hyeon, T. Chem. Commun. 2003, 652.

(12) Han, B. H.; Zhou, W.; Sayari, A. J. Am. Chem. Soc. 2003, 125, 3444

(13) Tanaike, O.; Hatori, H.; Yamada, Y.; Shiraishi, S.; Oya, A. Carbon $\mathbf{2 0 0 3}, 41,1759$.

(14) Tanaike, O.; Yoshizawa, N.; Hatori, H.; Yamada, Y.; Shiraishi, S.; Oya, A. Carbon 2002, 40, 457.

(15) Hlavaty, J.; Havan, L. Carbon 1999, 37, 1029.

(16) Miao, J. Y.; Cai, Y.; Chan, Y. F.; Sheng, P.; Wang, N. J. Phys. Chem. B 2006, 110, 2080.

(17) Sui, Y. C.; Acosta, D. R.; Gonzalez-Leon, J. A.; Bermudez, A.; Feuchtwanger, J.; Cui, B. Z.; Flores, J. O.; Saniger, J. M. J. Phys. Chem. B 2001, 105, 1523 .

(18) Rajesh, B.; Thampi, K. R.; Bonard, J. M.; Xanthopoulos, N.; Mathieu, H. J.; Viswanathan, B. J. Phys. Chem. B 2003, 107, 2701.

(19) Che, G.; Laksmi, B. B.; Martin, C. R.; Rodney, R. S.; Fisher, E. R. Chem. Mater. 1998, 10, 260.

(20) Miller, S. A.; Young, V. Y.; Martin, C. R. J. Am. Chem. Soc. 2001 123,12335 .

(21) Lee, J. S.; Gu, G. H.; Kim, H.; Jeong, K. S.; Bae, J.; Suh, J. S. Chem. Mater. 2001, 13, 2387.

(22) Jeong, S. H.; Lee, O. J.; Oh, S. H.; Park, C. G.; Lee, K. H. Chem. Mater. 2002, 14,1859

(23) Yang, Q.; Xu, W.; Tomita, A.; Kyotani, T. J. Am. Chem. Soc. 2005 $127,8956$.

(24) Wang, L. S.; Lee, C. Y.; Chiu, H. T. Chem. Commun. 2003, 1964.

(25) Peter, K.; Vollhardt, C.; Schore, N. E. Organic Chemistry, 3rd ed.: Freeman Press: New York, 1998; pp 325-326.

(26) Mckee, G. S. B.; Vecchio, K. S. J. Phys. Chem. B 2006, 110, 1179.

(27) Gregg, S. J.; Sing, K. S. W. Adsorption, Surface Area, and Porosity; Academic Press: London, UK, 1982; Chapter 3.

(28) Polarz, S.; Smarsly, B.; Schattka, J. H. Chem. Mater. 2002, 14, 2940.

(29) Shiraishi, S.; Kurihara, H.; Tsubota, H.; Oya, A.; Soneda, Y ; Yamada, Y. Electrochem. Solid-State Lett. 2001, 4, A5.

(30) Foley, H. C. Microporous Mater. 1995, 4, 407.

(31) Weast, R. C. CRC Handbook of Chemistry and Physics, 1st Student ed.; CRC Press: Boca Raton FL, 1988.

(32) Iijima, S. Nature 1991, 354, 56

(33) Iijima, S.; Ichihashi, T. Nature 1993, 363, 603.

(34) Ge, J. J.; Hou, H.; Li, Q.; Graham, M. J.; Greiner, A.; Reneker, D H.; Harris, F. W.; Cheng, S. Z. D. J. Am. Chem. Soc. 2004, 126, 15754

(35) Zhang, W. D.; Shen, L.; Phang, I. Y.; Liu, T. Macromolecules 2004, 37,256 